\title{
Mycoplasma synoviae surface protein MSPB as a recombinant antigen in an indirect ELISA
}

\author{
Amir H. Noormohammadi, † Philip F. Markham, Jillian F. Markham, \\ Kevin G. Whithear and Glenn F. Browning
}

Author for correspondence: Amir H. Noormohammadi. Tel: +6139345 2475. Fax: +61393470852. e-mail: amir_h(a wehi.edu.au

School of Veterinary Science, The University of Melbourne, Parkville, Victoria, Australia 3052

\begin{abstract}
Mycoplasma synoviae is a poultry pathogen causing respiratory disease and synovitis. A number of serological assays have been developed for diagnosis of $M$. synoviae infection; however, they lack sensitivity and/or are prone to false-positive reactions. Using a combination of PCR and expression cloning, four overlapping regions (regions 1-4) of the surface antigen MSPB of $\boldsymbol{M}$. synoviae WVU-1853 were expressed in a bacterial expression system. Immunostaining of the resultant polypeptides with chicken sera raised against different M. synoviae strains, or Mycoplasma gallisepticum S6, suggested that region 4 contained a highly antigenic and species-specific domain (amino acids 178-213) of MSPB. A fusion protein of region 4 was expressed in the PMAL expression system and purified from cold-osmotic-shock fluids of Escherichia coli cells for use in an indirect ELISA. The potential of the purified antigen for detection of $M$. synoviae antibodies was assessed with sera obtained from chickens experimentally infected with different strains of $M$. synoviae or $M$. gallisepticum, or from uninoculated chickens. All the sera from $M$. synoviaeinoculated chickens provided higher absorbance values than those from $M$. gallisepticum-inoculated or uninoculated chickens. Chickens inoculated with $\boldsymbol{M}$. synoviae $86079 / 7$ NS had detectable increases of serum anti-MSPB immunoglobulins at day 7 after inoculation. These studies have identified the most antigenic region of one of the major species-specific surface proteins of $M$. synoviae, and shown the potential of this protein as a serodiagnostic reagent.
\end{abstract}

Keywords: Mycoplasma synoviae, surface antigens, MSPB, ELISA, serology

\section{INTRODUCTION}

Mycoplasma synoviae is an important cause of chronic respiratory disease and synovitis in chicken, and causes a major economic loss in the poultry industry throughout the world. Control of this pathogen is highly dependent on serological assays to detect infected flocks; however, these assays suffer from limited specificity and sensitivity. The low specificity of current serological assays is mainly attributed to cross-reactions with Mycoplasma gallisepticum (Kleven, 1997).

†Present address: WEHI, Post Office, Royal Melbourne Hospital, VIC 3050, Australia.

Abbreviations: HRP, horseradish peroxidase; RSA, rapid serum agglutination; RU, relative units; SPF, specific-pathogen-free.

The GenBank accession number for the v/hA gene sequence is AF035624.
Several ELISAs have been developed to detect antibodies against $M$. synoviae, but they have generally been based on poorly defined membrane components. A number of earlier studies of $M$. synoviae ELISAs used crude membrane preparations (Opitz et al., 1983; Patten et al., 1984; Higgins \& Whithear, 1986), produced by either osmotic lysis or sonication of whole cells, or Triton X100-solubilized membrane proteins (Opitz \& Cyr, 1986) of $M$. synoviae, as antigens. These studies suggested that ELISA may serve as a sensitive assay for detection of $M$. synoviae infection. Using SDS-PAGE, Avakian \& Kleven (1990) purified three membrane antigens of $M$. synoviae F10-2AS (p53, p41 and p22) and used them in a dotELISA. Whilst assays using p53 and p22 were not sensitive, that based on p41 was more sensitive than the haemagglutination inhibition test in detecting antibodies to M. synoviae. In a recent study (Gurevich et al., 1995) directed at improving the specificity and sensitivity of 
the $M$. synouiae ELISA, a protein fraction highly enriched in an immunodominant cluster of $M$. synoviae WVU-185.3 proteins (p46-52) was extracted from the Triton X-114 detergent phase of this organism and further purified by ion-exchange chromatography. Results of an indirect ELISA, based on the purified fraction as antigen, showed a strong correlation $(r=$ $0.776)$ with results of the rapid serum agglutination (RSA) test on individual sera.

Although these ELISA systems are rapid and sensitive, they are relatively expensive to produce and, in some cases, have limited specificity (Kleven \& Yoder, 1989). In addition, studies on $M$. synoviae surface proteins (Noormohammadi et al., 1997) have highlighted the variable expression of major antigens of this organism and thus suggested that it may be difficult to ensure consistency of antigen preparations from cultures of $M$. synotiae.

A recent study in our laboratory (Noormohammadi et al., 1997) revealed that the immunodominant $42-56 \mathrm{kDa}$ cluster of $M$. synoviae WVU-1853 consists of two major membrane antigens, MSPA and MSPB, and that MSPB was expressed in all $M$. synoviae strains tested. These results suggested the potential of MSPB as a diagnostic antigen (Noormohammadi et al., 1997). Subsequently, the DNA sequence of the gene $(v l h A)$ which encodes both MSPB and MSBA was determined (Noormohammadi et al., 1998).

The aim of this study was to determine the most antigenic region of MSPB and to assess the potential of a serological test based on this antigen, in comparison to the RSA.

\section{METHODS}

Bacterial strains and growth media. Escherichia coli strain DH $5 x$ or JM109 was electrotransformed with recombinant plasmid and grown at $37^{\circ} \mathrm{C}$ in rich broth containing $50 \mu \mathrm{g}$ ampicillin ml (Sambrook et al., 1989). Rich broth contained (1 ') $10 \mathrm{~g}$ tryptone (Oxoid), $5 \mathrm{~g}$ yeast extract (Oxoid), $5 \mathrm{~g}$ $\mathrm{NaCl}$ and $2 \mathrm{~g}$ glucose.

M. synowiae strain WVU-1853, modified live vaccines MS-H (Vaxsafe MS) and BC-MS, and field isolates 69808 and 86079/7NS (Gurevich et al., 1995), and $M$. gallisepticum strain S6, field isolates NS-2, MGL (80083) and AP3AS (Soeripto et al., 1989), and modified live vaccine ts-11 (Vaxsafe MG) (Whithear et al., 1990) were grown in mycoplasma broth to the late-exponential growth phase (Whithear, 1993) and used for inoculation of chickens. Identity of each species was confirmed by immunofluorescence or growth inhibition test, as described previously (Whithear, 1993).

PCR. On the basis of the $v^{\prime} / h A$ gene sequence, a single forward oligonucleotide primer, $F_{1}$, was used in separate $P C R$ reactions with either of the oligonucleotide primers $\mathrm{R}_{1}, \mathrm{R}_{2}, \mathrm{R}_{3}$ or $\mathrm{R}_{4}$, to amplify four overlapping $5^{\prime}$ regions of the $M$. synoviae WVU185.3 ilh A gene that encode part of MSPB (Noormohammadi et al., 1998). Table 1 describes the oligonucleotide primers used for PCR amplification, and their target sites within the llh A gene. PCR was performed using Taq DNA polymerase (Promega) as described previously (Noormohammadi et al., 1998).
Expression cloning of fragments spanning the MSPB gene. For expression of polypeptides from regions $1-4$ of the $v / h A$ gene, the relevant PCR product was first purified using BioSpin 6 chromatography columns (Bio-Rad) and ligated to the plasmid vector PinPoint Xa1 T (Promega) as instructed by the manufacturer. Electrotransformation of E. coli JM109 cells with the ligation mixture was performed as described previously (Sambrook et al., 1989), and the resultant colonies were inoculated into rich broth and screened for expression of novel polypeptides by SDS-PAGE of their whole-cell proteins followed by Coomassie blue staining, or by Western blotting and probing with antibodies specific for MSPB (see immunoblotting section). Attempted purification of the biotinylated fusion protein of region 4 was performed by affinity chromatography using streptavidin beads (Promega) as instructed by the manufacturer.

For expression of region 4 in the pMAL-p2 expression system (New England BioLabs), an $853 \mathrm{bp}$ fragment of $v / \mathrm{h} A$ was obtained by digestion of a PinPoint Xa $1 \mathrm{~T}$ plasmid containing the $5^{\prime}$ end of the gene (Noormohammadi et al., 1998) with two restriction endonuclease enzymes, Bam HI and HindIII. The resultant fragments were subjected to electrophoresis through a $0.8 \%$ agarose gel as described before (Sambrook et al., 1989); the 853 bp fragment was excised from the gel, purified using the Wizard DNA clean-up system kit (Promega) and ligated to the compatibly digested plasmid vector $\mathrm{pMAL}-\mathrm{p} 2$ as instructed by the manufacturer. The ligated plasmid was used to transform E. coli DH $5 \alpha$ cells and the resultant colonies were screened for expression of the polypeptide as described above. Using amylose resin beads (New England BioLabs) as instructed by the manufacturer, the resultant fusion protein was purified from cold-osmotic-shock fluids from a culture of cells containing the recombinant plasmid.

SDS-PAGE and immunoblotting. E. coli whole-cell proteins and purified MSPB fusion protein were analysed by SDSPAGE or immunoblotting as described previously (Gurevich et al., 1995). Mouse mAbs 97 and 334, rabbit anti-MSPB polyclonal serum and chicken anti-M. gallisepticum, antiWVU-1853, anti-7NS and anti-BC-MS sera were used in immunostaining experiments. The origin of the mAbs 97 arid 334 has been described previously (Gurevich et al., 1995). Monospecific polyclonal antisera to MSPB were produced by immunizing rabbits with proteins excised from nitrocellulose membranes as described previously (Noormohammadi et al., 1997). Anti-M. gallisepticum was a pool of sera from specificpathogen-free (SPF) chickens that had been infected with $M$. gallisepticum S6. Anti-WVU, anti-7NS and anti-BC-MS were from SPF chickens infected with $M$. synoviae WVU-1853, $86079 / 7 \mathrm{NS}$ or BC-MS, respectively. Normal serum was from a single uninoculated SPF bird that had been found negative for M. gallisepticum and M. synoviae by RSA.

Test sera. Thirteen groups of chicken sera (named groups 1-13) were used in ELISA experiments, all of which were obtained from SPF Hybrid White Leghorn-type chickens (Commonwealth Scientific and Industrial Organization, Animal Health Division, Victoria, Australia). Sera against $M$. synoviae (groups 1-5 and 8-13) or M. gallisepticum (group 6) strains/isolates were raised by eye-drop inoculation with mycoplasma cultures.

Groups 1-5, each consisting of five to seven serum samples, were from chickens infected with $M$. synoviae BC-MS, $86079 / 7 \mathrm{NS}$, MS-H, WVU-1853 or 69808 , respectively (Table 
Table 1. Sequence, target site and orientation of the PCR oligonucleotide primers

\begin{tabular}{|lcrl|}
\hline Name & Orientation & Target site & \\
\hline F & Forward & $78-103$ & TGGATCCCAAACTCCAGCACCTGAAC \\
R1 & Reverse & $409-392$ & CGCTTAATGCTTTTACAG \\
R2 & Reverse & $529-511$ & CATCTTCTAGTAATGCTGT \\
R3 & Reverse & $636-618$ & TGGTTTAACTGCTGCAACT \\
R4 & Reverse & $1045-1026$ & GTTTGAATTCTGATTTGTCT \\
\hline
\end{tabular}

"Forward and reverse refer to orientation of the coding and complementary strands, respectively. † Positions of bases correspond to the nucleotide sequence of the $v l h A$ gene and are relative to the ATG initiation codon.

Table 2. Statistical analysis of $R U$ values of sera groups 1-7

\begin{tabular}{|c|c|c|c|c|c|}
\hline Group & Inoculum ${ }^{*}$ & $n \dagger$ & Mean & SE & Range \\
\hline 1 & M. synoviae $\mathrm{BC}-\mathrm{MS}$ & 6 & $2013 \cdot 00$ & $640 \cdot 00$ & $289-3862$ \\
\hline 2 & M. synoviae $86079 / 7 \mathrm{NS}$ & 5 & $448 \cdot 40$ & $95 \cdot 30$ & $179-691$ \\
\hline 3 & M. synoviae MS-H & 7 & $273 \cdot 60$ & $77 \cdot 20$ & $112-691$ \\
\hline 4 & M. synoviae WVU-1853 & 6 & $1316 \cdot 00$ & $763 \cdot 00$ & $229-5092$ \\
\hline 5 & M. synoviae 69808 & 6 & $256 \cdot 10$ & 73.60 & $56-479$ \\
\hline 6 & M. gallisepticum strains & 10 & $27 \cdot 60$ & $7 \cdot 39$ & $3-77$ \\
\hline 7 & - & 10 & $8 \cdot 10$ & $1 \cdot 66$ & $2-18$ \\
\hline
\end{tabular}

* Mycoplasma strain/isolate used for raising antibodies in chickens of each group.

$\uparrow$ Number of serum samples in each group.

2). Group 6 consisted of 10 serum samples from five pairs of chickens infected with $M$. gallisepticum NS-2, AP3AS, MGL, ts-11 or S6. Sera from groups 1-6 were all collected 4 weeks post-inoculation. Group 7 contained 10 serum samples from uninoculated chickens that were kept as uninfected controls. Groups 8-13 each consisted of nine or ten serum samples from chickens infected with $M$. synoviae $86079 / 7$ NS. Serum samples were collected immediately before inoculation (group 8) and at days 7 (group 9), 10 (group 10), 17 (group 11), 24 (group 12) and 28 (group 13) post-inoculation, respectively. All of the sera had been previously tested for $M$. synoviae and M. gallisepticum antibodies using the RSA assay as described previously (Whithear, 1993).

The M. synoviae-positive control serum was obtained from an SPF chicken inoculated with $M$. synoviae WVU-1853 as described above, and the $M$. synoviae-negative control serum was from an uninoculated chicken. These sera were examined for anti-M. synoviae antibodies by RSA, immunoblotting and ELISA assays.

Before use in ELISA, all serum samples were thawed, centrifuged at $16000 \mathrm{~g}$ for $30 \mathrm{~min}$ at $4{ }^{\circ} \mathrm{C}$ and diluted appropriately in ELISA buffer $[0.1 \mathrm{M}$ Tris, pH $7 \cdot 4(\mathrm{HCl})$; $0.5 \mathrm{M} \mathrm{NaCl} ; 1 \mathrm{mM} \mathrm{Na}{ }_{2}$ EDTA; $\%$ (w/v) BSA; $3 \%(\mathrm{v} / \mathrm{v})$ Triton X-100; and $3 \%(\mathrm{v} / \mathrm{v})$ Tween 20].

ELISA protocol. Wells of a 96-well flat-bottom plate (MaxiSorp; Nunc Inter Med) were coated with $100 \mu \mathrm{l}$ antigen (purified MSPB fusion protein) diluted in carbonate buffer $\left(0.032 \mathrm{M} \mathrm{Na}_{2} \mathrm{CO}_{3}, 0.068 \mathrm{M} \mathrm{NaHCO}_{3}, \mathrm{pH} 9.6\right)$ and the plate was incubated overnight at $4{ }^{\circ} \mathrm{C}$. The wells were washed three times with $200 \mu \mathrm{l} 0.05 \%$ Tween 20 in PBS and incubated for $1 \mathrm{~h}$ at room temperature with $200 \mu \mathrm{l}$ per well of $1 \%(\mathrm{w} / \mathrm{v}) \mathrm{BSA}$ in PBS. The wells were washed as before and incubated for $3 \mathrm{~h}$ at room temperature with $100 \mu \mathrm{l}$ per well of each dilution of test serum. After washing (as before) $100 \mu$ l horseradishperoxidase (HRP)-conjugated rabbit anti-chicken $\mathrm{IgG}$ (Chemicon) diluted in ELISA buffer was added to each well and the plate was incubated for $1 \mathrm{~h}$ at room temperature. The wells were washed as before, $100 \mu \mathrm{l}$ substrate [ $1 \mathrm{mg} 3,3^{\prime}, 5,5^{\prime}$ tetramethylbenzidine dihydrochloride (Sigma) in $10 \mathrm{ml}$ of the buffer recommended by the manufacturer with $0.006 \%(\mathrm{v} / \mathrm{v})$ $\mathrm{H}_{2} \mathrm{O}_{2}$ ] was added to each well and the plate was incubated for $5 \mathrm{~min}$ at room temperature. The enzymic reaction was stopped after 5 min with the addition of $25 \mu \mathrm{l} 2 \mathrm{M} \mathrm{H}_{2} \mathrm{SO}_{4}$ to each well and the $A_{450}$ of the contents of each well was measured. The $M$. synoviae-positive serum, the $M$. synoviae-negative serum and a conjugate control (containing antigen and conjugated antibody only) were included in each plate.

Determination of test sera reactivity. Analysis of ELISA results was performed using the program Delta Soft 3 (Dr E. Bechtold and BioMetallics). Each serum was tested at a 1/800 dilution. If the difference in absorbance of duplicate wells was greater than $10 \%$ of their respective mean value, the serum was assayed again. The mean absorbance of the duplicate conjugate control was subtracted from the absorbances of the assayed sera. The $M$. synoviae-positive serum was assayed in duplicate at $1 / 800$ and serial twofold dilutions to $1 / 204800$, to provide a series of standards on each plate. The four- 
parameter curve fit method was applied to the series of standards to obtain a standard curve, and means of the absorbances of duplicate serum dilutions were interpolated on the standard curve to express the reactivity of the test sera in units relative to the $M$. synoviae-positive serum. These calculations were performed to eliminate minor variations in conditions of the ELISA procedure between different plates. The reactivity of the $M$. synoviae-positive serum was defined as 1600 relative units $(\mathrm{RU})$ of $\operatorname{IgG} \mu \mathrm{l}^{\prime}$. Sera with out-of-range absorbance values (values within $\pm 1 \%$ of the maximum absorbance value for the $M$. synoviae-positive serum or more, and values within $\pm 1 \%$ of the minimum absorbance value for the $M$. synouiae-positive serum or less) were re-tested at three lower or higher twofold serial dilutions.

RSA test. The RSA tests for antibodies to $M$. gallisepticum and $M$. synowiae were performed using commercial reagents (Intervet International) as described previously (Whithear, 1993).

\section{RESULTS}

\section{Determination of the most antigenic region of MSPB}

To assess the antigenicity of different regions of the $\mathrm{MSPB}$, and their reaction with M. gallisepticum-infected chicken sera, MSPB was expressed as a panel of smaller fusion proteins. Four pairs of oligonucleotide primers were used to amplify four overlapping regions of the 'llh $A$ gene which did not contain TGA codons at their $5^{\prime}$ end (TGA encodes tryptophan in mycoplasmas). The resultant PCR products were ligated to the expression vector PinPoint $\mathrm{Xa} 1 \mathrm{~T}$, and this was used to transform E. coli JM109 cells. Regions 1-4 (Fig. 1a) were predicted to encode polypeptides of 110 (amino acids 27-137), 150 (amino acids 27-177), 185 (amino acids 27-212) and 290 (amino acids 27-317) amino acids, respectively, in $E$. coli cells. SDS-PAGE of the whole-cell proteins of E. coli cells containing the recombinant plasmids demonstrated the expression of fusion proteins of approximately 32 , 35,38 and $50 \mathrm{kDa}$ from the plasmids containing regions $1-4$, respectively. Immunostaining of Western blots of the whole-cell proteins of the clones expressing polypeptides from regions $1-4$ (Fig. 1 b) showed that anti- $M$. gallisepticum or normal chicken sera detected a number of $E$. coli proteins, but not any of the fusion proteins. Anti-7NS and anti-BC-MS chicken sera similarly bound a number of $E$. coli proteins, but also the $50 \mathrm{kDa}$ fusion protein, and weakly bound the $38 \mathrm{kDa}$ fusion protein. No reaction could be detected between these sera and the 32 and $35 \mathrm{kDa}$ fusion proteins. In contrast, sera from chickens infected with $M$. synoviae WVU-1853 bound intensely to all four fusion proteins. Similar experiments using MSPB-specific mAbs 97 and 334 revealed that they bound only the $50 \mathrm{kDa}$ fusion protein (results not shown).

\section{Purification of the highly antigenic region of MSPB}

An attempt was made to purify the fusion protein of region 4 using the PinPoint $\mathrm{Xa}$ protein purification system; however, due to the low yield of the purified fusion protein and the presence of persistent con- taminants, an alternative expression and purification system, pMAL, was used to obtain a purified fusion protein (containing the polypeptide expressed from region 4) in sufficient quantity for use in an ELISA. An $853 \mathrm{bp}$ fragment of the $v$ lhA gene was obtained as described in Methods and polypeptide was expressed from it in $E$. coli cells using the pMAL expression vector (Fig. 2, lane 2). The resultant fusion protein was partially purified by cold-osmotic-shock lysis of E. coli cells (lane 3 ) and further purified by affinity chromatography using amylose resin beads (lane 4 ). Approximately $25 \mu \mathrm{g}$ pure fusion protein was obtained per $\mathrm{ml}$ of culture used. Immunostaining of Western blots of the affinity-purified fusion protein did not reveal any reactivity with anti- $M$. gallisepticum or preinoculation chicken sera, but reacted with anti-WVU-1853, anti-7NS and anti-BC-MS chicken sera (results not shown).

\section{Optimization of antigen concentration, test serum and anti-chicken conjugate antibody dilutions for an indirect ELISA (MSPB-ELISA)}

The recombinant fusion protein was used at a concentration of $16 \mu \mathrm{g} \mathrm{ml}^{-1}$, and at 10 twofold dilutions to $0.03 \mu \mathrm{g} \mathrm{ml}^{-1}$, to coat duplicate wells of a microtitre ELISA plate. The bound antigen was tested with the $M$. synoviae-positive and -negative sera diluted at 1/1000. Chicken $\operatorname{IgG}$ bound to the antigen was detected with HRP-conjugated rabbit anti-chicken $\operatorname{IgG}$ diluted $1 / 500$. The antigen concentration that provided the lowest non-specific binding of the $M$. synoviae-negative sera and maximum absorbance with the $M$. synoviaepositive serum was determined to be approximately $4 \mu \mathrm{g}$ $\mathrm{ml}^{-1}$ (Fig. 3a).

The M. synoviae-positive and -negative sera were assayed at $1 / 50$ and at serial twofold dilutions to $1 / 819200$ and $1 / 12800$, respectively, using the antigen at optimal concentration and conjugate at $1 / 500 \mathrm{di}$ lution. The maximum absorbance of the $M$. synoviaepositive serum and the minimum non-specific reaction of the $M$. synoviae-negative serum were obtained at $1 / 800$ and $1 / 1600$ serum dilutions (Fig. 3b).

To determine the optimal dilution of the HRPconjugated rabbit anti-chicken $\lg$, the assay was performed with antigen at a concentration of $4 \mu \mathrm{g} \mathrm{ml}^{-1}$, the $M$. synoviae-positive and-negative sera at a dilution of $1 / 800$, and the conjugate at five serial twofold dilutions, from $1 / 200$ to $1 / 3200$ (Fig. 3c). The optimal dilution of the conjugate was determined to be $1 / 800$.

\section{Differentiation of sera from $\boldsymbol{M}$. synoviae-infected, $M$. gallisepticum-infected and uninoculated chickens by MSPB-ELISA}

Using the optimal conditions for antigen and conjugate described above, sera from groups $1-7$ were examined at three dilutions, $1 / 800,1 / 1600$ and $1 / 3200$, and the amount of MSPB antibodies present in these sera was interpolated from absorbance values using the standard 
(a)

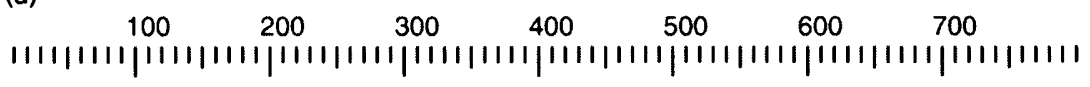

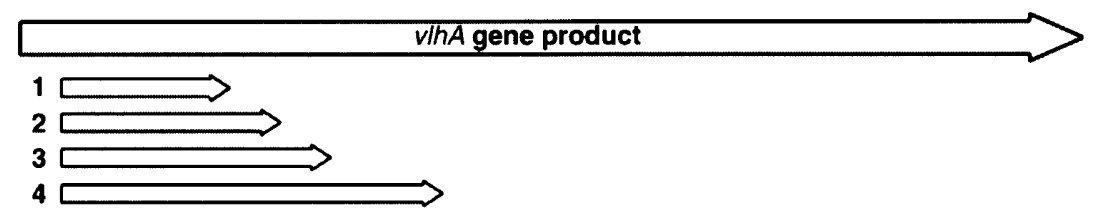

(b)
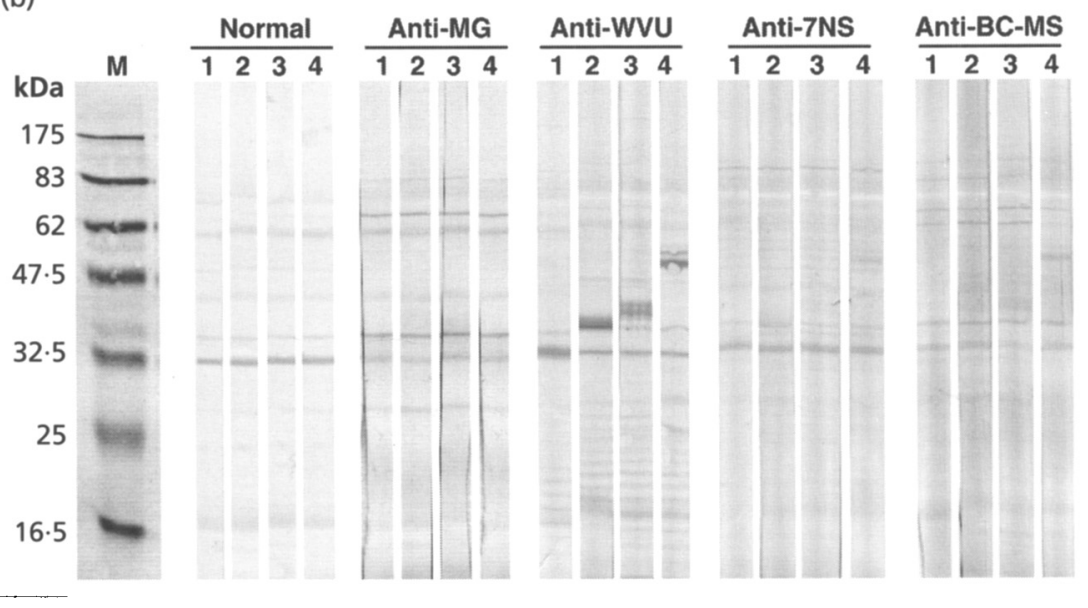

Fig. 1. Expression and detection of the four overlapping regions of the vIhA gene. (a) The vlhA gene product (large arrow) and regions 1-4 (small arrows below) expressed in $E$. coli cells using the plasmid vector PinPoint Xa1 T. The scale on the top indicates the number of amino acid residues. (b) Immunoblots of whole-cell proteins of the $E$. coli cells expressing fusion proteins of regions 1-4 (lanes 1-4 in each panel, respectively) from recombinant plasmid PinPoint Xa1 T. Each panel was probed with serum from uninoculated chickens or with sera from chickens inoculated with $M$. gallisepticum S6 (MG), $M$. synoviae WVU-1853, 86079/7NS or BC-MS. The lane marked $M$ shows the prestained broad range protein molecular mass markers (New England BioLabs).

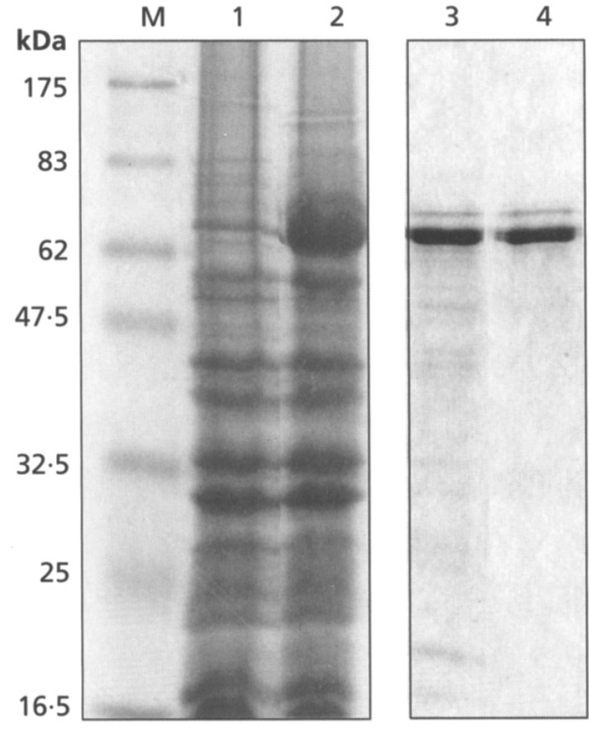

Fig. 2. SDS-PAGE followed by Coomassie brilliant blue staining of the purification steps of the MSPB fusion protein. $E$. coli cells containing the recombinant plasmid PMAL (lane 1) were induced to express the MSPB fusion protein (lane 2) and then subjected to cold-osmotic-shock lysis. The fluid resulting from cold-osmotic-shock lysis was extracted (lane 3 ) and the fusion protein was affinity-purified (lane 4) using amylose resin beads. The lane marked $M$ shows the prestained broad range protein molecular mass markers (New England BioLabs).

curve. A typical standard curve derived from the $M$. synoviae-positive serum is shown in Fig. 3(d). The mean, standard error and range of RU for each group are shown in Table 2. The mean RU of groups 1-5 (obtained from M. synoviae-infected chickens) was 710 . Groups 1 and 4 had the highest RU while groups 3 and 5 had the lowest RU. The mean RU of each of groups 1-5 was higher than that of group 6 (obtained from $M$. gallisepticum-infected chickens) or 7 (obtained from uninoculated chickens). All 30 individual sera from groups 1-5, except for one sample from group 5 with 56 RU, contained $95 \mathrm{RU}$ or more. In contrast, all 10 individual sera from group 7 contained $18 \mathrm{RU}$ or less. Sera from group 6 had a mean of $28 \mathrm{RU}$ and tended to give higher $\mathrm{RU}$ values than those from uninoculated chickens. Nine out of 10 serum samples tested from group 6 had $52 \mathrm{RU}$ or less with one serum sample containing 77 RU. Fig. 4 compares the upper and lower limits of interquartile ranges and confidence intervals for sera groups $1-7$.

The Spearman's rank coefficient of correlation between the RU values and RSA scores of the individual sera from groups 1-7 was 0.803 , indicating a strong correlation between the two tests for these groups.

\section{Detection of seroconversion in M. synoviae-infected birds by MSPB-ELISA}

To examine the kinetics of development of antibodies against MSPB after infection with $M$. synoviae, sera from groups 8-13 were tested in the MSPB-ELISA as described above. The mean, standard error and range of RU for each group are shown in Table 3. Comparison of the RU values of the sera from these groups revealed an increase in MSPB antibodies at day 7 post-inoculation 

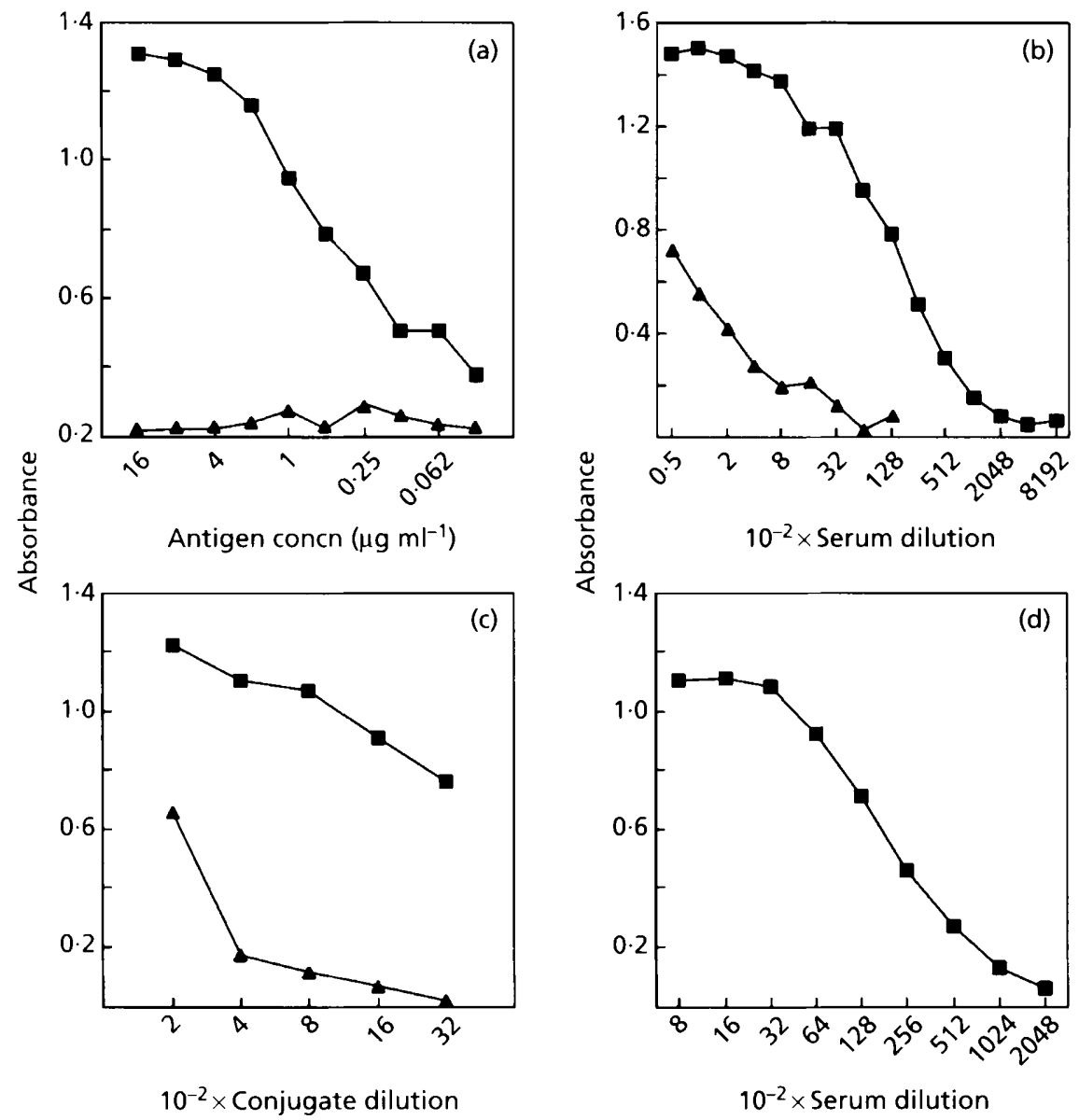

Fig. 3. Optimization of MSPB-ELISA parameters. (a) Optimization of antigen concentration. The $M$. synoviae-positive and -negative sera were diluted to $1 / 1000$ and incubated with the titrated MSPB fusion protein. Reactivity of serum IgG was detected by indirect ELISA using HRP-conjugated rabbit anti-chicken IgG diluted 1/500. (b) Optimization of test serum dilution. The $M$. synoviae-positive and -negative sera were assayed in serial twofold dilutions with the antigen at a concentration of $4 \mu \mathrm{g} \mathrm{ml}^{-1}$, and conjugate at a dilution of $1 / 500$. (c) Optimization of the conjugate. Antigen (at a concentration of $4 \mu \mathrm{g} \mathrm{ml}^{\prime}$ ) and the $M$. synoviae-positive and -negative sera (diluted 1/800) were titrated against five serial twofold dilutions of the conjugate. (d) An example of the standard curve obtained for each microtitre plate from serial twofold dilutions of the $M$. synoviae-positive serum. $\mathbf{\square}$, Positive serum; $\boldsymbol{\Delta}$, negative serum.

Table 3. Statistical analysis of RU values of sera groups 8-13

\begin{tabular}{|cccrrc|}
\hline Group & PI $(\mathbf{d})^{*}$ & $\boldsymbol{n} \dagger$ & Mean & \multicolumn{1}{c|}{ SE } & Range \\
8 & 0 & 8 & $6 \cdot 25$ & $1 \cdot 28$ & $3-14$ \\
9 & 7 & 8 & $63 \cdot 60$ & $11 \cdot 40$ & $27-107$ \\
10 & 10 & 9 & $487 \cdot 60$ & $43 \cdot 20$ & $275-675$ \\
11 & 17 & 9 & $1076 \cdot 00$ & $284 \cdot 00$ & $200-3009$ \\
12 & 24 & 9 & $1113 \cdot 00$ & $397 \cdot 00$ & $127-3927$ \\
13 & 28 & 9 & $1403 \cdot 00$ & $404 \cdot 00$ & $151-3190$ \\
\hline
\end{tabular}

*Post-inoculation (d).

$\dagger$ Number of serum samples in each group.

and a sharp rise at days 10 and 17 post-inoculation. Fig. 5 compares the upper and lower limits of interquartile ranges and confidence intervals for sera groups $8-13$.
The Spearman's rank coefficient of correlation was 0.797 , indicating a strong correlation between the two tests for these sera groups.

\section{DISCUSSION}

Several studies have reported increased sensitivity of $M$. synoviae ELISAs using different antigen preparations (Opitz et al., 1983; Patten et al., 1984; Higgins \& Whithear, 1986; Opitz \& Cyr, 1986; Avakian \& Kleven, 1990; Gurevich et al., 1995); however, specificity continues to be a problem associated with $M$. synoviae ELISAs.

Our previous study (Noormohammadi et al., 1997) suggested the potential of MSPB as a diagnostic reagent to detect infection caused by different $M$. synoviae strains. In this study, immunostaining of four different regions of MSPB revealed that only the polypeptide expressed from region 4 was detected by all sera from 


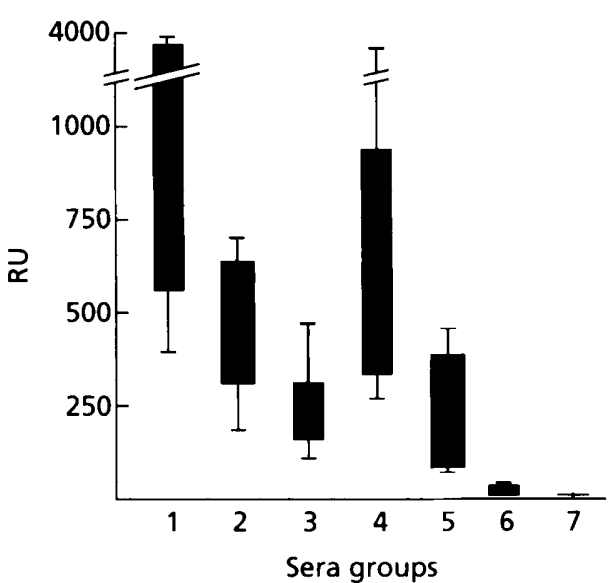

Fig. 4. Boxplots of the RU values of sera from chickens inoculated with $M$. synoviae BC-MS (group 1), 86079/7NS (group 2), MS-H (group 3), WVU-1853 (group 4) or 69808 (group 5), or with $M$. gallisepticum (group 6), or from uninoculated chickens (group 7) measured in the MSPB-ELISA. Rectangles represent the interquartile range (the range of the middle $50 \%$ of the data) of each group. The $95 \%$ confidence interval of each group is shown by lines extended from the sides of the rectangles.

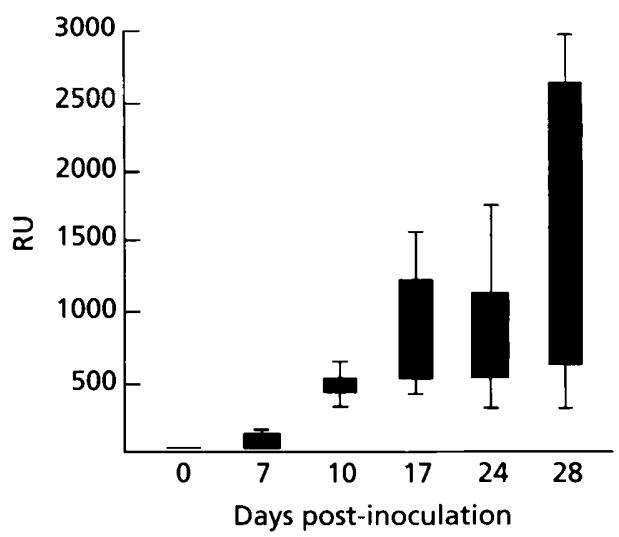

Fig. 5. Boxplots of the $R U$ values of sera from chickens inoculated with $M$. synoviae $86079 / 7$ NS and collected at days 0 , $7,10,17,24$ or 28 post-inoculation. Rectangles represent the interquartile range of each group. The $95 \%$ confidence interval of each group is shown by lines extended from the sides of the rectangles.

chickens infected with the $M$. synoviae strains used, while the polypeptides from regions 1,2 and 3 were only detected by serum raised against the homologous strain used for DNA cloning (WVU-1853). The difference observed in reactivity of MSPB from M. synoviae WVU1853 with sera from birds infected with different $M$. synoviae strains could be related to the phenomenon of antigenic variation described previously (Noormohammadi et al., 1997). Also it was shown that region 4 , but not regions 1, 2 or 3, contained epitopes for the MSPB-specific mAbs 97 and 334. These observations suggest that the region between amino acids 212 and 317 is highly antigenic and contains the epitopes which are most cross-reactive between different $M$. synoviae strains and best recognized by chickens during the course of infection. Whilst the fusion protein of region 4 was found to be highly antigenic, it did not bind anti-M. gallisepticum or normal chicken sera, suggesting that a polypeptide expressed from region 4 can serve as a species-specific antigen.

The potential of the MSPB fusion protein, expressed from the vlhA gene in $E$. coli cells, had to be further assessed in an ELISA using a panel of sera from chickens infected with different strains of M. gallisepticum and M. synoviae. Hence, an indirect ELISA (MSPB-ELISA) was devised and optimized in terms of antigen, conjugate and test serum concentrations. A battery of sera from chickens experimentally infected with $M$. synoviae or M. gallisepticum, and from uninoculated chickens, were examined in the MSPB-ELISA. The results were encouraging from two points of view. Firstly, with a margin of $40 \mathrm{RU}$, all but one of the $M$. synoviaeinoculated chicken sera had higher RU than sera from uninoculated and $M$. gallisepticum-infected chickens. The only exception was a single serum from a chicken infected with M. synoviae 69808 which had 56 RU. As this serum had an RSA score of one, the low RU value seen in the MSPB-ELISA could well be due to an exceptionally low $M$. synoviae antibody titre in this particular serum. Secondly, unlike some other prokaryotic purification tags, such as the glutathione $S$ transferase protein used in the pGEX expression and purification system (Pharmacia Biotech) (Browning, 1994), the maltose-binding protein (expressed with the MSPB fusion protein as a purification tag) did not bind non-specifically to antibodies from chicken sera.

Lower levels of MSPB antibodies were seen in chickens inoculated with M. synoviae 69808 and MS-H. Given that these groups also had lower RSA values, this observation may reflect the limited ability of $M$. synoviae 69808 and MS-H to elicit antibodies, at least in the serum of the experimentally infected chickens.

In order to study the kinetics of seroconversion of chickens infected with $M$. synoviae, sera from chickens were collected at different time points after inoculation with $M$. synoviae $86079 / 7 \mathrm{NS}$, and tested in the MSPBELISA. Comparison of the RU values of these sera showed that MSPB antibodies could be detected by day 7 post-inoculation, with the highest level in this experiment observed around day 28 post-inoculation. There was a relatively strong correlation between the RSA scores and RU values of the individual sera from these sera. These results revealed that the MSPB-ELISA could be as sensitive as the RSA in its ability to detect $M$. synoviae antibodies in chicken sera early in infection.

The results from the study presented here suggest that the MSPB-ELISA could be a reliable substitute for antigens used in current $M$. synoviae ELISAs. The MSPB fusion protein has several advantages over previously described M. synoviae -ELISA antigens, including reproducibility (as it overcomes the problem of phase 
variation which affects the yield and/or immunoreactivity of the $M$. synoviae native antigen), cost and ease of preparation. Additionally, it provides specific and relatively sensitive detection of $M$. synoviae antibodies.

\section{REFERENCES}

Avakian, A. P. \& Kleven, S. H. (1990). Fvaluation of SDSpolyacrylamide gel electrophoresis purified proteins of $\mathrm{MycO}$ plasma gallisepticum and Mycoplasma synoviae as antigens in a dot ELISA. Av'ian Dis 34, 575-584.

Browning, G. F. (1994). Development of new reagents for serological diagnosis of mycoplasma infections. In Proceedings of the 9th European Poultry Conference, pp. 277-280. Glasgow: The World's Poultry Science Association.

Gurevich, V. A., Ley, D. H., Markham, J. F., Whithear, K. G. \& Walker, I. D. (1995). Identification of Mycoplasma synoviae immunogenic surface proteins and their potential use as antigens in the enzyme-linked immunosorbent assay. Avian Dis 39, $46.5-474$.

Higgins, P. A. \& Whithear, K. G. (1986). Detection and differentiation of Mycoplasma gallisepticum and Mycoplasma synoviae antibodies in chicken serum using enzyme-linked immunosorbent assay. Alian Dis 30, 160-168.

Kleven, S. H. (1997). Mycoplasma synoviae infection. In Diseases of Poultry, pp. 220-228. Edited by B. W. Calnek, H. J. Barnes, C. W. Beard, W. M. Reid \& H. W. Yoder, Jr. Ames, IA: Iowa State University.

Kleven, S.H. \& Yoder, J. H.W. (1989). Mycoplasmosis. In A Laboratory Manual for the Isolation and Identification of Avian Pathogens, pp. 57-62. Edited by H. G. Purchase, L. H. Arp, C. H. Domermuth \& J. E. Pearson. Dubuque, IA: Kendall/Hunt.
Noormohammadi, A. H., Markham, P. F., Whithear, K. G., Walker, I. D., Gurevich, V. A., Ley, D. H. \& Browning, G. F. (1997). Mycoplasma synoviae has two distinct phase-variable major membrane antigens, one of which is a putative hemagglutinin. Infect Immun 65, 2542-2547.

Noormohammadi, A. H., Markham, P. F., Duffy, M. F., Whithear, K. G. \& Browning, G. F. (1998). Multigene families encoding the major hemagglutinins in phylogenetically distinct mycoplasmas. Infect Immun 66, 3470-3475.

Opitz, H. M. \& Cyr, M. J. (1986). Triton X-100-solubilized Mycoplasma gallisepticum and Mycoplasma synotiae ELISA antigens. Avian Dis 30, 213-215.

Opitz, H. M., Duplessis, J. B. \& Cyr, M. J. (1983). Indirect microenzyme-linked immunosorbent assay for the detection of antibodies to Mycoplasma synoviae and Mycoplasma gallisepticum. Avian Dis 27, 773-786.

Patten, B. E., Higgins, P. A. \& Whithear, K. G. (1984). A ureaseELISA for the detection of mycoplasma infections in poultry. Aust Vet J 61, 151-155.

Sambrook, J., Fritsch, E. F. \& Maniatis, T. (1989). Molecular Cloning: a Laboratory Manual, 2nd edn. Cold Spring Harbor, NY: Cold Spring Harbor Laboratory.

Soeripto, Whithear, K. G., Cottew, G. S. \& Harrigan, K. E. (1989). Virulence and transmissibility of Mycoplasma gallisepticum. Aust Vet J 66, 65-72.

Whithear, K. G. (1993). Avian mycoplasmosis. In Australian Standard Diagnostic Techniques for Animal Diseases, pp. 1-12. Edited by L. A. Corner \& T. J. Bagust. East Melbourne: CSIRO for the Standing Commitee on Agriculture and Resource Management.

Whithear, K. G., Soeripto, Harrigan, K. E. \& Ghiocas, E. (1990). Safety of temperature sensitive mutant Mycoplasma gallisepticum vaccine. Aust Vet J 67, 159-165.

Received 2 February 1999; revised 16 April 1999; accepted 20 April 1999. 